\title{
Erythrocyte Ghost Count
}

National Cancer Institute

\section{Source}

National Cancer Institute. Erythrocyte Ghost Count. NCI Thesaurus. Code C96605.

The determination of the amount of erythrocyte ghosts (erythrocytes in which hemoglobin has been removed through hemolysis) present in a sample. 